\title{
Perbandingan Nilai Akademik Mahasiswa PSKD FKK UMJ Pembelajaran Tatap Muka dengan Pembelajaran Jarak Jauh
}

\author{
Rayhana $^{1}$, Ihsan Alwi ${ }^{2}$ \\ ${ }^{1}$ Fakultas kedokteran dan kesehatan Universitas Muhammadiyah Jakarta \\ ${ }^{2}$ Mahasiswa Fakultas kedokteran dan Kesehatan Muhammadiyah Jakarta \\ Email: raykud@gmail.com, ihsanalwi14@gmail.com
}

\begin{abstract}
Background: Education is an effort to create a conducive learning atmosphere and design a learning process so that students are able to develop their potential. The development of TIK in learning supports the creation of the e-learning method, but pros and cons arise in it so that it disturbs the skills aspects of students. For that we need an evaluation of the changes in the learning method. Methods: This study is a quantitative analytic study with a crosssectional approach. The sample selection was carried out by total sampling from the entire population, namely the 2018 FKK-UMJ medical students, which amounted to around 143 students. Data were analyzed using SPSS v.25 and statistical tests using the Independent Sample T-test. Results: Differences in the practical-exam-scores and tutorial-scores of PSKD FKK-UMJ students class of 2018 when doing face-to-face learning of the Tropical Medicine System and distance learning of the Urogenital System. The practical-exam-score was better in distance learning of the Urogenital System with the A predicate (44.1\%) while the tutorial score was better in the face-to-face learning of the Tropical Medicine System with the A predicate (85.3\%). Bivariate analysis, practicum-exam-scores and tutorial-scores for the two systems with two different learning methods were different with $\operatorname{Sig}(2$-tailed) $<0.05$. Conclusion: There are differences in the comparison of the practicalexam-scores and the tutorial scores of the 2018 PSKD FKK-UMJ students during face-to-face learning in the Tropical Medicine System and distance learning on the Urogenital System.
\end{abstract}

Key Words: Face-to-face learning, distance learning, tutorials, practicum.

Abstrak. Latar Belakang: Pendidikan adalah usaha mewujudkan suasana belajar kondusif serta merancang proses pembelajaran agar peserta didik mampu mengembangkan potensinya. Perkembangan TIK dalam pembelajaran mendukung terciptanya metode e-learning namun timbul pro dan kontra didalamnya sehingga mengganggu aspek keterampilan peserta didik. Untuk itu diperlukan evaluasi terhadap perubahan metode pembelajaran tersebut. Metode Penelitian: Penelitian ini termasuk jenis kuantitatif analitik dengan pendekatan cross sectional. Pemilihan sampel dilakukan dengan total sampling dari keseluruhan populasi yang ada yaitu mahasiswa kedokteran FKK UMJ angkatan 2018 yang berjumlah sekitar 143 mahasiswa. Data dianalisis menggunakan SPSS v.25 dan uji statistik menggunakan uji Independent Sample T-test. Hasil Penelitian: Terdapat perbedaan nilai ujian praktikum dan nilai tutorial mahasiswa PSKD FKK UMJ angkatan 2018 saat melakukan pembelajaran tatap muka Sistem Kedokteran Tropis dan pembelajaran jarak jauh Sistem Urogenital. Nilai ujian praktikum lebih baik pada pembelajaran jarak jauh Sistem Urogenital dengan predikat A $(44,1 \%)$ sedangkan nilai tutorial lebih baik pada pembelajaran tatap muka Sistem Kedokteran Tropis dengan predikat A (85,3\%). Hasil analisis bivariat, nilai ujian praktikum dan nilai tutorial kedua sistem dengan dua metode pembelajaran yang berbeda terdapat perbedaan dengan Sig (2-tailed) < 0,05. Kesimpulan: Terdapat perbedaan komparasi nilai ujian praktikum dan nilai tutorial mahasiswa PSKD FKK UMJ angkatan 2018 saat pembelajaran tatap muka Sistem Kedokteran Tropis dan pembelajaran jarak jauh Sistem Urogenital.

Kata Kunci: Pembelajaran Tatap Muka, Pembelajaran Jarak Jauh, Tutorial, Praktikum. 


\section{PENDAHULUAN}

Pada dasarnya kegiatan pembelajaran dilakukan secara langsung atau pembelajaran tatap muka dalam kelas dimana dosen menjelaskan materi pelajaran melalui berbagai media dan mahasiswa secara pasif mendengarkan penjelasan dosen tersebut dan diakhir pembelajaran diadakan tanya jawab interaktif antara dosen dan mahasiswa (Khusniyah, 2019). Sejak kasus pertama Covid19 di Indonesia di konfirmasi pada tanggal 2 Maret 2020 kemudian pemerintah menetapkan pandemi severe acute respiratory syndrome coronavirus (SARS-CoV-2) atau yang biasa disebut Covid-19, Program Studi Kedokteran (Pskd) Fakultas Kedokteran dan Kesehatan Universitas Muhammadiyah Jakarta (FKK UMJ) menggunakan metode Pembelajaran Jarak Jauh (PJJ) (Kemenkes, 2020)

Fakultas Kedokteran dan Kesehatan Universitas Muhammadiyah Jakarta (FKK UMJ) berdiri pada tanggal 5 September 2003 dengan menyelenggarakan angkatan pertama Program Studi Kedokteran. Penyelenggaraan Program Studi Kedokteran di FKK UMJ menggunakan sistem Kurikulum Berbasis Kompetensi (KBK) dengan penyelenggaraan metode Kuliah, Problem Based Learning (PBL), Praktikum, dan Keterampilan Klinik didalamnya.

\section{METODE}

Penelitian ini termasuk jenis kuantitatif analitik dengan pendekatan cross sectional dengan cara mengambil data variabel dependen dan variabel independen yang dilakukan sekali waktu pada saat yang bersamaan. Variabel dependen melihat distribusi nilai ujian praktikum sistem kedokteran tropis dan sistem urogenital mahasiswa PSKd FKK UMJ angkatan 2018 tahun ajaran 2019-2020 dan melihat distribusi nilai tutorial sistem kedokteran tropis dan sistem urogenital mahasiswa PSKd FKK UMJ angkatan 2018 tahun ajaran 2019-2020. Variabel independent melihat distribusi nilai tutorial sistem kedokteran tropis dan sistem urogenital mahasiswa PSKd FKK UMJ angkatan 2018 tahun ajaran 2019-2020.

Pemilihan sampel dilakukan dengan total sampling dari keseluruhan populasi yang ada yaitu mahasiswa kedokteran FKK UMJ angkatan 2018 yang berjumlah sekitar 143 mahasiswa.

Kriteria Inklusi : Mahasiswa program studi Kedokteran FKK UMJ angkatan 2018 kelas Cirendeu dan Cempaka Putih dan telah mengikuti Sistem Kedokteran Tropis dan Sistem Urogenital serta memiliki nilai ujian praktikum dan nilai tutorial.

Kriteria Eksklusi:

Mahasiswa yang tidak memiliki nilai lengkap pada Sistem Kedokteran Tropis dan Sistem Urogenital.

Sampel dalam penelitian ini dipilih berdasarkan metode total sampling dari 143 mahasiswa Kedokteran FKK UMJ angkatan 2018. Data dalam penelitian ini merupakan data sekunder, berupa nilai ujian praktikum dan nilai tutorial Sistem Kedokteran Tropis dan Sistem Urogenital mahasiswa PSKd FKK UMJ angkatan 2018 tahun ajaran 2019-2020 yang diperoleh dari bagian akademik FKK UMJ.

Seluruh data penelitian yang telah terkumpul akan dilakukan analisis data menggunakan program SPSS versi 25. Analisis data terdiri dari analisis univariat dan analisis bivariat dengan uji statistik menggunakan uji Independent Sample T-test.

\section{HASIL DAN PEMBAHASAN}

Tabel 1. Distribusi Nilai Ujian Praktikum Pembelajaran Tatap Muka Sistem Kedokteran Tropis Angkatan 2018

\begin{tabular}{|c|c|c|}
\hline Rentang Nilai & Jumlah (n) & Presentase $(\%)$ \\
\hline $0-44,99$ & 149,8 & \\
\hline $45-55,99$ & 11,2 & \\
\hline $56-67,99$ & 31,5 & \\
\hline $68-79,99$ & 32,2 & \\
\hline $80-10022$ & 15,4 & \\
\hline Total & 143 & \\
\hline
\end{tabular}

Tabel 2. Distribusi Nilai Tutorial
Pembelajaran Tatap Muka Sistem Kedokteran Tropis Angkatan 2018

\begin{tabular}{|llll}
\hline Rentang Nilai & Jumlah (n) & Presentase (\%) \\
\hline O-44,99 & O & O & \\
\hline $45-55,99$ & O & O & \\
\hline $56-67,99$ & 2 & 1,4 \\
\hline $68-79,99$ & 19 & 13,3 \\
\hline $80-100122$ & 85,3 & \\
\hline Total & 143 & 100 \\
\end{tabular}


Tabel 3 Distribusi Nilai Ujian Praktikum Pembelajaran Jarak Jauh Sistem Urogenital Angkatan 2018

\begin{tabular}{|c|c|c|}
\hline Rentang Nilai & Jumlah (n) & Presentase $(\%)$ \\
\hline $0-44,99$ & $1 \quad 0,7$ & \\
\hline $45-55,99$ & 3,5 & \\
\hline $56-67,99$ & 18,2 & \\
\hline $68-79,99$ & 33,6 & \\
\hline $80-10063$ & 44,1 & \\
\hline Total & 143 & \\
\hline
\end{tabular}

Tabel 4. Distribusi Nilai Tutorial
Pembelajaran Jarak Jauh Sistem Urogenital Angkatan 2018

\begin{tabular}{|llll|}
\hline Rentang Nilai Jumlah (n) & Presentase (\%) \\
\hline $0-44,99$ & 0 & 0 & \\
\hline $45-55,99$ & 0 & 0 \\
\hline $56-67,99$ & 0 & 0 \\
\hline $68-79,99$ & 25 & 17,5 \\
\hline $80-100118$ & 82,5 & \\
\hline Total & 143 & 100 \\
\hline
\end{tabular}

Tabel 5. Komparasi Nilai Ujian Praktikum Pembelajaran Tatap Muka Sistem Kedokteran Tropis dan Pembelajaran Jarak Jauh Sistem Urogenital Mahasiswa Kedokteran FKK UMJ Angkatan 2018

Asumsi Sig (2-tailed)

Praktikum Kedokteran Tropis dan Urogenital Asumsi varian sama 0,000

Asumsi varian berbeda 0,000

Berdasarkan tabel 5 mengenai komparasi nilai ujian praktikum pembelajaran tatap muka Sistem Kedokteran Tropis dan pembelajaran jarak jauh Sistem Urogenital mahasiswa Kedokteran FKK UMJ angkatan 2018 tahun ajaran 2019-2020 dilakukan uji statistic menggunakan Independent Sample T-test didapatkan Sig (2-tailed) 0,000 menandakan < 0,05 .

Maka dapat disimpulkan bahwa terdapat perbedaan signifikan antara nilai ujian praktikum Sistem Kedokteran Tropis dengan Sistem Urogenital pada mahasiswa Kedokteran FKK UMJ angkatan 2018. Perbedaaan menandakan nilai ujian praktikum Sistem Urogenital jauh lebih baik dibandingkan Sistem Kedokteran Tropis. Perbedaan ini didasarkan pada penyelenggaraan kedua metode pembelajaran yang berbeda. Sistem Kedokteran Tropis dilaksanakan secara tatap muka, sedangkan Sistem Urogenital dilaksanakan secara pembelajaran jarak jauh.

Tabel 6 Komparasi Nilai Tutorial Pembelajaran Tatap Muka Sistem Kedokteran Tropis dan Pembelajaran Jarak Jauh Sistem Urogenital Mahasiswa Kedokteran FKK UMJ Angkatan 2018

Asumsi

Sig (2-tailed)

Tutorial Kedokteran Tropis dan Urogenital Asumsi varian sama $\quad 0,002$

Asumsi varian berbeda $\quad 0,002$

Berdasarkan tabel 4.6 mengenai komparasi nilai tutorial pembelajaran tatap muka Sistem Kedokteran Tropis dan pembelajaran jarak jauh Sistem Urogenital mahasiswa Kedokteran FKK UMJ angkatan 2018 tahun ajaran 2019-2020 dilakukan uji statistic menggunakan Independent Sample T-test didapatkan Sig (2-tailed) 0,002 menandakan < 0,05 .

Maka dapat disimpulkan bahwa terdapat perbedaan signifikan antara nilai tutorial Sistem Kedokteran Tropis dengan Sistem Urogenital pada mahasiswa Kedokteran FKK UMJ angkatan 2018. Dari perbedaan komparasi ini, diketahui bahwa nilai tutorial mahasiswa Kedokteran FKK UMJ angkatan 2018 lebih tinggi pada Sistem Kedokteran Tropis dengan metode pembelajaran tatap muka. Sedangkan rata-rata presentasi nilai tertinggi untuk tutorial Sistem Urogenital lebih rendah karena dilaksanakan secara pembelajaran jarak jauh.

Berdasarkan hasil analisis Uji Independent Sampel T-test terhadap komparasi nilai ujian praktikum pembelajaran tatap muka Sistem Kedokteran Tropis dengan nilai ujian praktikum pembelajaran jarak jauh Sistem Urogenital mahasiswa Kedokteran FKK UMJ angkatan 2018 didapatkan nilai Sig (2-tailed) 0,000 hal ini menandakan terdapat perbedaan signifikan antara nilai ujian praktikum di kedua sistem tersebut. Ditinjau berdasarkan presentasi mahasiswa yang mendapatkan predikat nilai A dalam ujian praktikum maka Sistem Urogenital lebih baik dengan presentasi $(44,1 \%)$ dibandingkan dengan Sistem Kedokteran Tropis 
dengan presentasi $(15,4 \%)$ berdasarkan nilai ujian praktikum.

Perbedaan ini didasarkan karena perbedaan dalam penyelenggaraan kedua sistem tersebut. Sistem Kedokteran Tropis diselenggarakan selama 6 SKS dengan metode pembelajaran tatap muka, sedangkan Sistem Urogenital diselenggarakan juga sebanyak 6 SKS namun dengan metode pembelajaran jarak jauh. Sesuai dengan penjabaran sebelumnya, perbedaan nilai ujian praktikum pada Sistem Urogenital lebih unggul dimungkinkan karena beberapa faktor, seperti kesiapan mahasiswa lebih matang karena disediakan rekaman kuliah praktikum oleh bagian akademik sehingga mahasiswa dapat melihat dan memahami nya berulang-ulang, berbeda dengan praktikum Sistem Kedokteran Tropis yang diselenggarakan secara tatap muka selama 3x50 menit, sehingga mahasiswa dituntut langsung memahami serta melakukan belajar mandiri diluar jam kegiatan praktikum.

Selain faktor internal terdapat faktor eksternal yang menyebabkan perbedaan nilai ujian praktikum dikedua sistem tersebut. Seperti lingkungan keluarga yang mungkin dapat membantu mahasiswa saat kegiatan ujian praktikum, serta kemungkinan untuk melakukan open book saat ujian berlangsung, dimana hal ini terjadi karena mereka merasa kurangnya pengawasan dari pihak laboran, akademik, atau pihak lainnya.

Berdasarkan hasil analisis Uji Independent Sampel T-test terhadap komparasi nilai tutorial pembelajaran tatap muka Sistem Kedokteran Tropis dengan nilai tutorial pembelajaran jarak jauh Sistem Urogenital mahasiswa Kedokteran FKK UMJ angkatan 2018 didapatkan nilai Sig (2-tailed) 0,002 hal ini menandakan terdapat perbedaan signifikan antara nilai tutorial di kedua sistem tersebut. Ditinjau berdasarkan presentasi mahasiswa yang mendapatkan predikat nilai A dalam tutorial maka Sistem Kedokteran Tropis lebih unggul dengan presentasi $(85,3 \%)$ dibandingkan dengan Sistem Urogenital dengan presentasi $(82,5 \%)$.

Perbedaan komparasi ini didasarkan karena kedua sistem berbeda dalam pola penyelenggaraan perkuliahan. Tutorial Sistem Kedokteran Tropis dilaksanakan secara tatap muka, sedangkan tutorial Sistem Urogenital dilaksanakan secara pembelajaran jarak jauh. Presentasi mahasiswa dengan predikat A pada tutorial Sistem Kedokteran Tropis lebih unggul dikarenakan mahasiswa mendapatkan kesempatan langsung tutorial di kampus. Hal seperti ini mendorong keingintahuan mahasiswa akan suatu hal meningkat. Tersedianya banyak referensi pendukung tutorial di perpustakaan kampus menyebabkan pengetahuan mahasiswa bertambah dan beragam antar mahasiswa sesuai dengan referensi yang mereka baca. Perbedaan referensi dan keragaman pemahaman akan suatu skenario tutorial inilah yang menyebabkan mahasiswa menjadi aktif dalam kegiatan tutorial.

Selain itu peran tutor juga sangat berpengaruh dalam kegiatan tutorial tatap muka pada Sistem Kedokteran Tropis. Tutor dapat mengawasi secara langung bagaimana progress mahasiswa dari pertemuan satu ke pertemuan dua melalui belajar mandiri yang mereka lakukan, serta secara tidak langsung mahasiswa dituntut untuk melakukan empat teori dasar tutorial yaitu kolaboratif, mandiri, konstruktif, dan konstektual. Beda hal nya dengan tutorial Sistem Urogenital yang dilaksanakan secara daring. Mahasiswa kurang bisa untuk melakukan empat teori dasar kegiatan tutorial, serta akses yang terbatas terhadap referensi bacaan untuk memecahkan permasalahan dalam skenario tutorial. Kegiatan tutorial secara daring secara tidak langsung menyebabkan mahasiswa kehilangan tanggung jawab untuk mempresentasikan materi secara langsung dalam sebuah flip chart berdasarkan konsep dari sebuah materi, melainkan hanya menampilkan materi melalui tampilan powerpoint dan cenderung membaca materi dari catatan yang telah mereka siapkan sebelumnya.

Hal ini tidak dapat disamakan untuk semua mahasiswa, namun dari pengamatan yang saya lakukan beberapa alasan diatas dapat menjadi alasan utama mengapa nilai tutorial pembelajaran tatap muka Sistem Kedokteran Tropis lebih baik dibandingkan nilai tutorial pembelajaran jarak jauh Sistem Urogenital.

Saya selaku peneliti belum menemukan penelitian yang sejenis dengan penelitian ini, dikarenakan jenis penelitian ini tergolong baru dan diteliti saat terjadi perubahan metode 
pembelajaran dalam institusi pendidikan. Dan penelitian ini hanya dilakukan pada program studi Kedokteran FKK UMJ angkatan 2018.

\section{KESIMPULAN}

1. Terdapat perbedaan nilai ujian praktikum mahasiswa Kedokteran FKK UMJ angkatan 2018 saat pembelajaran tatap muka Sistem Kedokteran Tropis dan pembelajaran jarak jauh Sistem Urogenital. Presentasi nilai ujian praktikum dengan predikat A pada pembelajaran tatap muka Sistem Kedokteran Tropis sebanyak $15,4 \%$, sedangkan predikat nilai A pada ujian praktikum pembelajaran jarak jauh Sistem Urogenital sebesar 44,1\%. Dari hasil ini, ujian praktikum pembelajaran jarak jauh Sistem Urogenital lebih baik daripada Sistem Kedokteran Tropis.

2. Terdapat perbedaan nilai tutorial mahasiswa Kedokteran FKK UMJ angkatan 2018 saat pembelajaran tatap muka Sistem Kedokteran Tropis dan pembelajaran jarak jauh Sistem Urogenital. Presentasi nilai tutorial mahasiswa dengan predikat A sebanyak 85,3\% pada Sistem Kedokteran Tropis yang diselenggarakan secara pembelajaran tatap muka. Sedangkan presentasi sebesar 82,5\% didapatkan dari tutorial Sistem Urogenital yang dilakukan secara pembelajaran jarak jauh. Dari hasil ini, nilai tutorial pembelajaran tatap muka Sistem Kedokteran Tropis lebih baik daripada tutorial Sistem Urogenital yang diselenggarakan secara jarak jauh.

3. Perbedaan hasil diatas dipengaruhi oleh perbedaan metode pembelajaran. Nilai ujian praktikum lebih unggul saat pembelajaran jarak jauh, hal ini dikarenakan mahasiswa mampu mendengar dan melihat rekaman kuliah praktikum sesering mungkin sehingga mereka lebih memahami materi, atau kurangnya pengawasan pihak laboran saat ujian berlangsung sehingga memungkinkan mahasiswa untuk melakukan open book. Sedangkan nilai tutorial lebih unggul saat pembelajaran tatap muka, hal ini dikarenakan mahasiswa mampu mencari referensi materi seluas mungkin, dan mampu menerapkan pembelajaran kolaboratif, konstruktif, mandiri, dan konstekstual dengan baik.

\section{SARAN}

Untuk penelitian selanjutnya, diharapkan menggunakan lebih banyak parameter dalam menentukan capaian pembelajaran peserta didik terhadap metode pembelajaran yang digunakan.

\section{UCAPAN TERIMA KASIH}

Terima kasih kepada pihak kampus yang telah membantu pengambilan data sehingga penelitian dapat diselesaikan.

\section{DAFTAR PUSTAKA}

Ahmad, N. (2015). Buku Ajar Evaluasi Pembelajaran. Yogyakarta: Interpena.

Ahmadi, A., Widodo, S. (2013) Psikologi Belajar. Jakarta: Rineka Cipta.

Ango, Mary L. (2002). Mastery of Science Process Skills and Their Effective Use in

the Teaching of science: An Educogy of Science Education in the Nigerian

Context. International Journal of Educolog. Vol.16. No.1:11-30.

Arikunto, S. (2019). Dasar-dasar Evaluasi Pendidikan Edisi Revisi. Yogyakarta:

Bumi Aksara.

Azhar, Arsyad. (2014). Media Pembelajaran. Jakarta: PT. Rajawali Pers.

Bilfaqih, Y. and Qomarudin, M. N. (2015) 'Esensi Pengembangan Pembelajaran

Daring', Deepublish, 1(1), p. 131.

Buku Panduan Akademik Program Studi Kedokteran Fakultas Kedokteran dan

Kesehatan Universitas Muhammadiyah Jakarta Tahun 2017-2018.

De Poter, B., Herancki, M. (1999). Quantum Learning. Yogyakarta: Kaifa.

Departemen Pendidikan Nasional. (2008). Pengembangan Model Pembelajaran

Tatap Muka, Penugasan Terstruktur dan Tugas Mandiri Tidak Terstruktur. Departemen Pendidikan Nasional. Direktorat Pembinaan Sekolah Menengah Atas.

Dikti, D. (2020). Buku Panduan

Penyelenggaraan Pembelajaran

Semester Gasal

2020/2021 di Perguruan Tinggi. p.29.

Direktorat Jenderal Pendidikan Tinggi

Kementerian Pendidikan dan

Kebudayaan. 
2010. Guidline Penguji OSCE Kedokteran. Jakarta: Dikti-Kemdikbud.

Ettiger, RHH. (2004). Psychology, Science Behavior and Life. Printed in United

States of America

Hamzah, B. U., (2010). Orientasi Baru Dalam Psikologi Siswa Yang Memiliki Gaya

Belajar. Jakarta: Bumi Aksara.

Harry, A. (2018). 'Esensi gaya belajar visual, auditori, dan kinestetik dalam

pengajaran keterampilan berbahasa di sekolah', Seminar Nasional Paramasastra 4, (July 2016), pp. 792-803.

J. Drysdale, et.al. (2013). An Analysis of Research Trends in Dissertation and Theses

Studying Blended Learning. The Internet and pg. 90-100. Higher Education. Volume 7,

Jamil, S. (2017). Strategi Pembelajaran; Teori dan Aplikasi. Yogyakarta: Ar-Ruzz

Media.

Kemendikbud, (2014). Standar Nasional Pendidikan Tinggi, Peraturan Menteri

Pendidikan dan Kebudayaan Republik Indonesia No. 49 Tahun 2014.

Kemenristekdikti. (2015). Standar Nasional Pendidikan Tinggi, Peraturan Menteri

Riset, Teknologi, dan Pendidikan Tinggi Republik Indonesia No. 44 Tahun 2015.

Khusniyah, N. L. and Hakim, L. (2019) 'Efektivitas Pembelajaran Berbasis Daring:

Sebuah Bukti Pada Pembelajaran Bahasa Inggris', Jurnal Tatsqif, 17(1), pp.

19-33. doi: 10.20414/jtq.v17i1.667.

Konstruktif, P. (2013). 'Tingkat Pelaksanaan Problem-Based Learning di Fakultas

Kedokteran Universitas Gadjah Mada Berdasarkan', 2(1), pp. 44-61.

Lee, Jean S. dkk. (2014). "Taking a Leap of Faith: Redefining Teaching and

Learning in Higher Education Through Project Based Learning",

Interdisciplinary Journal of Problem-Based Learning/ Vol. 8 No. 2, 8- 17.

Liew SC., Sidhu J., and Barua A., (2015). The Relationship between learning

preferences (styles and approaches) and learning outcomes among preclinical undergraduate medical students, BMC Medical Education, pp. 1-7.

Morgan. (2019). 'Teknik Dasar Pekerjaan Laboratorium Kimia', Journal of

Chemical Information and Modeling, 53(9), pp. 1689-1699.

Napitupulu, R. M. (2020) 'Dampak pandemi Covid-19 terhadap kepuasan

pembelajaran jarak jauh', Jurnal Inovasi Teknologi Pendidikan, 7(1), pp. 23\33. doi: 10.21831/jitp.v7i1.32771.

Nasir, A., Abdul, M., (2011). Dasar-dasar Keperawatan Jiwa: Pengantar dan Teori.

Jakarta: Salemba Medika.

Nasution, S. (2013). Berbagai Pendekatan Dalam Proses Belajar Mengajar.

Bandung: Bumi Aksara.

Ngalim, P., (2014). Psikologi Pendidikan. Bandung: Rosdakarya.

Prasetyo, Jan., dkk. (2017). Buku Ajar Psikiatri Klinis Ed 3 Cetakan Kedua. Jakarta:

Badan Penerbit FKUI.

Prawiyogi, A. G., et.al. (2020). 'Efektifitas Pembelajaran Jarak Jauh Terhadap

Pembelajaran Siswa di SDIT Cendekia Purwakarta', Jurnal Pendidikan

Dasar, 11(01), pp. 94-101.

Rusman. (2017). Model-Model Pembelajaran; Mengembangkan Profesionalisme

Guru. Jakarta: Rajawali Press.

Sabri, L. and Hastono, S. P. (2014) Statistik Kesehatan. Jakarta: Raja Grafindo

Persada.

Sagala, S. (2017). Konsep dan Makna Pembelajaran; Memecahkan Problematika

Belajar dan Mengajar Cetakan Ke-13. Bandung: CV Alfabeta.

Santoso, B. (2020). Pandemi dan Kurikulum Kedokteran. Available at:

https://www.jawapos.com/opini/13/08/2020/pan demi-dan-kurikulum

kedokteran/ (Accessed: 20 September 2020).

Smp, D. A. N. and Palu, N. (2016) 'Perbandingan Metode Pembelajaran Blended

Learning Menggunakan Powerpoint Dipandu Animasi Untuk Meningkatkan

Hasil Belajar Fisika Siswa Di Smp Negeri 7 Palu', pp. 35-44. 
Sugiyono, P., D. (2016). 'Metode Seleksi Mahasiswa Baru dan Sistem Penilaian',

Journal of Chemical Information and Modeling, 53(9), pp. 1689-1699.

Suhartono, (2016). Menggagas Pendekatan Blended Learning di Sekolah Dasar.

Prosiding Temu Ilmiah Nasional Guru (TING) VIII.

Sujarweni, W. (2014) Metodologi Penelitian Lengkap, Praktis, dan Mudah Dipahami.

Yogyakarta: PT Pustaka Baru.

Suryaningsih, Y. (2017). 'Pembelajaran Berbasis Praktikum Sebagai Sarana Siswa

untuk Berlatih Menerapkan Keterampilan Proses Sains dalam Materi

Biologi', Bio Educatio, 2(2), p. 279492.

Susanti, P. F. E. et al. (2017). 'Hubungan Kualitas Skenario Terhadap Keefektifan

Diskusi Problem- Based Learning (PBL) Blok Emergency Pada Mahasiswa

Fakultas Kedokteran Universitas Lampung the Relationship of Quality

Scenario to Effectiveness of the Problem- Based Learning (PBL) Disc',

Medulla, 7(4), pp. 157-163.

Sutikno, S. (2014). Metode \& Model-model Pembelajaran. Lombok: Holistika.

Syakir, Septian El., (2014). Islamic Hypno Parenting Mendidik Anak Masa Kini ala

Rasulullah, Jakarta: PT. Kawan Pustaka.

Tantri, N. R. (2018). Kehadiran Sosial dalam Pembelajaran Daring Berdasarkan

Sudut Pandang Pembelajar Pendidikan Terbuka dan Jarak Jauh. Jurnal Pendidikan Terbuka dan Jarak Jauh, 19(1), 19-30.

Undang-Undang Republik Indonesia Nomor 20 Tahun 2003 Tentang Sistem

Pendidikan Nasional. 